from wide uptake of this publication (including Cochrane, OMERACT, IDEOM, RADS, and the GRADE Working Group).

Musculoskeletal Statistics Unit, The Parker Institute is grateful for the financial support received from public and private foundations, companies and private individuals over the years. The Parker Institute is supported by a core grant from the Oak Foundation; The Oak Foundation is a group of philanthropic organizations that, since its establishment in 1983, has given grants to not-for-profit organizations around the world.

DOI: 10.1136/annrheumdis-2020-eular.809

\section{THU0615-HPR FORCE-TIME CURVE ANALYSIS OF HANDGRIP STRENGTH IN PATIENTS WITH FIBROMYALGIA: COMPARISON WITH HEALTHY SUBJECTS}

S. Farah ${ }^{1}$, M. DI Carlo ${ }^{1}$, F. Salaffi ${ }^{1}{ }^{1}$ Hospital "Carlo Urbani”, Scienze Cliniche e Molecolari, Università Politecnica delle Marche, Jesi, Italy

Background: Factors associated with handgrip strength (HGs), in female with fibromyalgia (FM), use of force-time (FeT) curve to assess peak force, area under the curve (AUC), and variability of the time to reach maximum plateau of the curves (Fig.1) (1) to identify the impact of FM patients versus healthy controls have not been extensively studied.

\section{Force-Time curve}

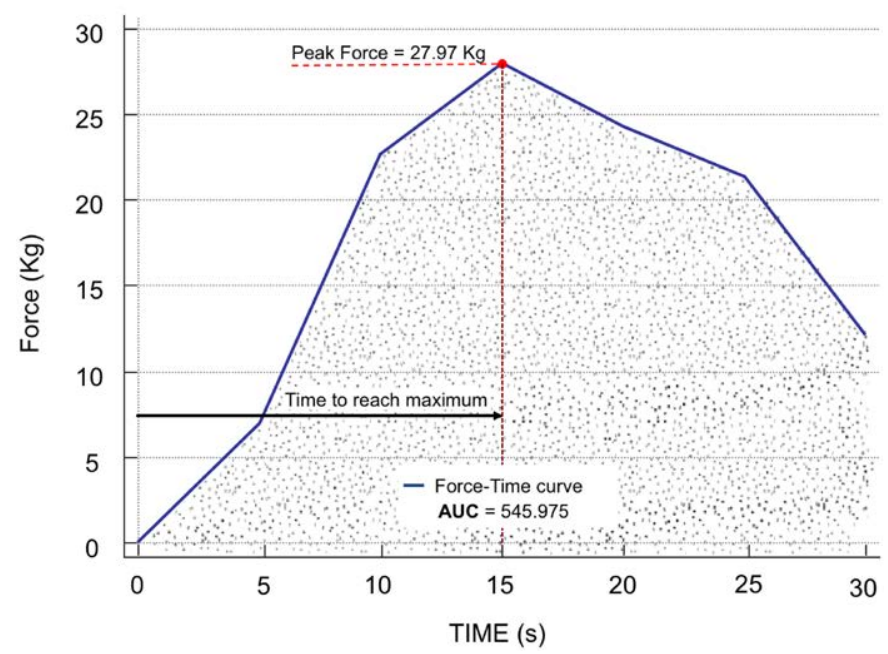

Figure 1. Force-time $(\mathrm{FeT})$ curve showing the method of calculation of the various force attributes.

Objectives: The aim of the study was to compare the HGs of FM with healthy subjects and to evaluate the relationship between curve characteristics and FM disease severity $(2,3)$.

Methods: One hundred and ten women (mean age $53.8 \pm 12.4$ years; range 18 to 80 ) were included and compared with 111, age and BMI matched, female healthy controls. HGs was measured with an electronic device, while demographic and clinical characteristics of the subjects were obtained by the Revised version of the Fibromyalgia impact questionnaire (FIQR) and Fibromyalgia Activity Score (FAS). The patient opinion of their symptoms state (PASS) was evaluated as external criterion. The HGs threshold that best discriminates between the presence and absence of FM, as well as between moderate and severe FM, was determined using the receiver operating characteristic (ROC) curves analyses. Multivariate regression procedure was used in order to assess the relative contribution of the covariates on the HGs.

Results: HGs-AUC and peak force levels were lower in patients with FM than healthy women (median 342.7 vs 496.5; and in $\mathrm{Kg}$ median was 13.9 vs 19.9 , respectively; both at significant level of $p<0.001$ ) and in women with severe $F M$ compared with those with mild-moderate FM $(p<0.0001)$. The time to reach maximum plateau of the curves was significantly higher in patients with FM than healthy women ( 15.5 vs $11.8 \mathrm{sec} ; \mathrm{p}>0.001$ ). ROC analyses revealed that the HGs peak force threshold that best discriminated between the presence and absence of FM was $14.2 \mathrm{~kg}$ (AUC $0.801 ; \mathrm{p}<0.001$ ), whereas the HGs peak force threshold that best discriminate between PASS was $16.3 \mathrm{~kg}$ (AUC 0.834; $p<0.001$ ). A negative correlation was found between FIQR and FAS scores and peak force, AUC in patients with FM (all at $p<0.001$ ). Furthermore, a correlation was observed between widespread pain index (WPI) and peak force, AUC (both at $p<0.0001$ ), and of the time to reach maximum plateau of the curves $(P=0.04)$ in patients with
FM. Factors significantly associated with HGs-AUC in multivariate analysis were WPI and FIQR (both at $\mathrm{p}<0.001$ ).

Conclusion: HGs is reduced in woman FM patients and is inversely related to FM severity and symptomatology. The FeT curve gave more information about grip in the FM and could be used as a complementary tool in the assessment and monitoring of FM. Further research on male FM patients is needed to confirm or contrast these findings.

Table 6. Correlations between HGs curve characteristics and questionnaires studied through the Spearman's rho correlation coefficients (rho).

\begin{tabular}{|c|c|c|c|c|c|}
\hline & FIQR & FAS & $\begin{array}{l}\text { HGs peak } \\
\text { force levels }\end{array}$ & $\begin{array}{l}\text { Time to reach } \\
\text { maximum plateau } \\
\text { of the curves }\end{array}$ & HGs-AUC \\
\hline WPI & $\begin{array}{c}0.732 \\
<0.0001\end{array}$ & $\begin{array}{c}0.823 \\
<0.0001\end{array}$ & $\begin{array}{l}-0.612 \\
<0.0001\end{array}$ & -0.1950 .0415 & $\begin{array}{l}-0.615 \\
<0.0001\end{array}$ \\
\hline FIQR & & $\begin{array}{c}0.761 \\
<0.0001\end{array}$ & $\begin{array}{c}-0.576 \\
<0.0001\end{array}$ & -0.0540 .5768 & $\begin{array}{c}-0.592 \\
<0.0001\end{array}$ \\
\hline FAS & & & $\begin{array}{c}-0.577 \\
<0.0001\end{array}$ & -0.1670 .0813 & $\begin{array}{c}-0.588 \\
<0.0001\end{array}$ \\
\hline HGs peak force levels & & & & -0.1510 .0249 & $\begin{array}{c}0.991 \\
<0.0001\end{array}$ \\
\hline $\begin{array}{l}\text { Time to reach maximum } \\
\text { plateau of the curves }\end{array}$ & & & & & $\begin{array}{l}-0.135 \\
0.0456\end{array}$ \\
\hline
\end{tabular}

References:

[1] Dias, J.J., Singh, H.P., Taub, N. \& Thompson, J. Grip strength characteristics using force-time curves in rheumatoid hands. J Hand Surg Eur Vol. 38, 170177 (2013)

[2] Salaffi, F., Di Carlo, M., Arcà, S. \& Galeazzi, M. Categorisation of disease severity states in fibromyalgia: a first step to support decision-making in health care policy. Clin Exp Rheumatol. 36, 1074-1081 (2018).

[3] Aparicio, V.A., Ortega, F.B., Heredia, J.M., Carbonell-Baeza, A., Sjöström, M \& Delgado-Fernandez, M. Handgrip strength test as a complementary tool in the assessment of fibromyalgia severity in women. Arch Phys Med Rehabil. 92, 83-98 (2011).

Disclosure of Interests: None declared

DOI: 10.1136/annrheumdis-2020-eular.4197

\section{THU0616-HPR EXPIRATORY FLOW ACCELERATOR (EFA) IN SYSTEMIC SCLEROSIS PATIENTS WITH MUCUS HYPERSECRETION, PRODUCTIVE COUGH AND DYSPNOEA: PRELIMINARY RESULTS FROM A HOME- BASED AIRWAY CLEARANCE TECHNIQUE DAILY PROGRAM}

S. Faverzani ${ }^{1}$, A. Becciolini ${ }^{1}$, E. Crisafulli ${ }^{2}$, F. Nocera ${ }^{1}$, E. DI Donato ${ }^{3}$, F. Mozzani ${ }^{1}$, M. Riva ${ }^{3}$, D. Santilli ${ }^{1}$, L. Monica ${ }^{1}$, A. Barbieri ${ }^{3}$, L. Barone ${ }^{3}$, M. Marvisi ${ }^{4}$, V. Alfieri ${ }^{1}$, A. Frizzelli ${ }^{1}$, A. Chetta ${ }^{1}$, A. Ariani ${ }^{1} .{ }^{1}$ Azienda Ospedaliero Universitaria of Parma, Parma, Italy; ${ }^{2}$ Azienda Ospedaliera Universitaria Integrata Verona, Verona, Italy; ${ }^{3}$ Azienda Ospedaliero Universitaria of Parma, Parma, Italy; ${ }^{4}$ Casa di Cura Figlie di San Camillo, Cremona, Italy

Background: Systemic sclerosis (SSc) is a chronic disease with frequent lung involvement. As mucociliary clearance is impaired, mucus retention and frequent pulmonary infections, increase morbidity and mortality (1).

Airway clearance techniques (ACT) enhance removal of mucus from the airways Expiratory flow accelerator (EFA) is a new technology that promotes deep and gentle drainage of the bronchial secretions, through the Venturi effect. No res piratory effort is required and no negative pressure is generated, avoiding risk of bronchial collapse (2).

Objectives: The aim of this study was to describe the effectiveness of EFA in improving pulmonary symptoms in SSc patients.

Methods: SSc patients with daily productive cough, frequent pulmonary exacerbations, exertional dyspnea and/or reduced physical activity were selected. All of them underwent a home-based ACT program with EFA. A Respiratory Physiotherapist (RT) trained each patient to use the device 3 times a day, 15 minutes each session. Every subject compiled the Saint George's Respiratory Questionnaire (SGRQ) and scleroderma Health Assessment Questionnaire (SHAQ) at baseline, 30, 90 and 180 days from the beginning. Statistical analysis has been carried out with General linear model for repeated measures. A value of $p<0.05$ was considered statistically significant.

Results: 8 patients were enrolled (M:F=1:7), median age 54 (IC95\% 46-69) years. Interstitial lung disease affected the majority of them (7/8). SGRQ total score and SHAQ domain for respiratory symptoms decreased over time 
$(p=0.003$ and $p=0.005)$. In particular, there was an improvement in two SGRQ domains: activities $(p=0.013)$ and symptoms $(p=0.005)$ (fig.1).

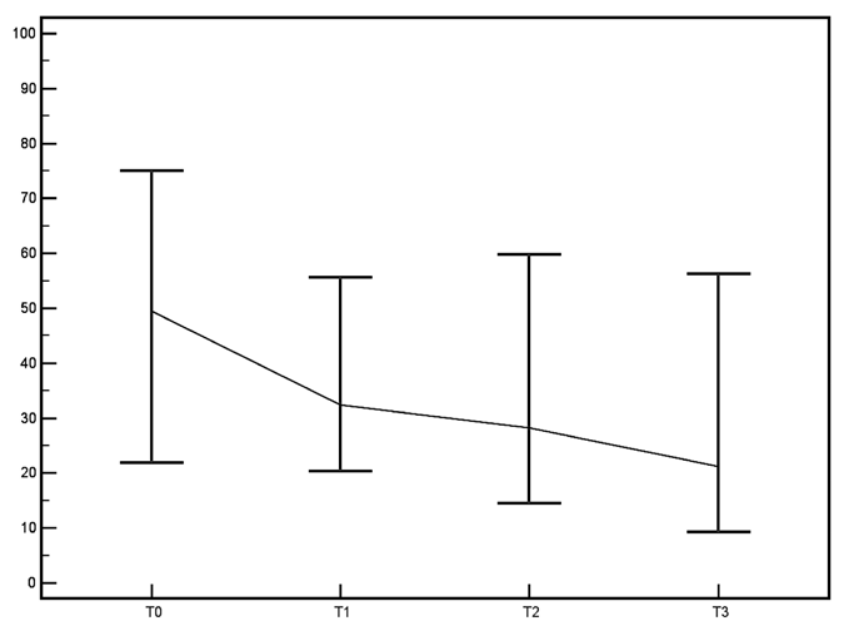

Figure 1

Conclusion: This is the first study to investigate the effect of EFA technology on airway clearance in SSc patients. The observations suggest the importance of a daily ACT program with EFA in improving respiratory symptoms. This technology appear to be extremely promising in SS patient management as it is well tolerated and it has the potential to slow down the pulmonary disease progression by limiting bronchial infections.

References:

[1] Tyndall AJ et al. Causes and risk factors for death in systemic sclerosis: a study from the EULAR Scleroderma Trials and Research (EUSTAR) database. Ann Rheum Dis 2010;69:1809-15.

[2] Zampogna E, et al. Expiratory Flow Accelerator (EFA) technique on mucus hypersecretion of COPD patients with reduced cough efficiency after a severe exacerbation. Int Clin Med 2019;3:1-6.

Disclosure of Interests: Silvia faverzani: None declared, Andrea Becciolini Speakers bureau: Sanofi-Genzyme, UCB and AbbVie, ernesto crisafulli: None declared, filippo nocera: None declared, eleonora di donato: None declared, Flavio Mozzani: None declared, michele riva: None declared, Daniele Santilli: None declared, lorenza monica: None declared, annalisa barbieri: None declared, lissette barone: None declared, maurizio marvisi: None declared, veronica alfieri: None declared, annalisa frizzelli: None declared, Alfredo Chetta: None declared, ALARICO ARIANI: None declared

DOI: 10.1136/annrheumdis-2020-eular.2434

\section{THU0617-HPR TOWARDS A UNIVERSAL DEFINITION OF DISEASE ACTIVITY SCORES THRESHOLDS}

N. Foulquier ${ }^{1}$, B. Chevet ${ }^{2}$, G. Carvajal Alegria ${ }^{1}$, L. Saraux ${ }^{3}$, V. DevauchellePensec $^{1}$, P. Redou ${ }^{1}$, A. Saraux ${ }^{1} .{ }^{1} \mathrm{CHU}$, Univ Brest and Inserm, Brest, France; ${ }^{2} \mathrm{CHU}$, Brest, France; ${ }^{2} \mathrm{CHU}$, Brest, France

Background: For rheumatologists monitoring patients with various diseases and dealing with multiple scores with different maximum values ( 9 for RA-DAS, 6.4 for AS-DAS and 60 for PMR-AS) and values thresholds to characterize the different levels of disease activity (low, intermediate and high) can be a tedious task. The same problematic could arise in other specialty than rheumatology. Normalization of these scores seems to be necessary to facilitate daily clinical practice (1).

Objectives: To indentify and standardize scores of activity of inflammatory diseases.

Methods: We conducted a literature review on activity criteria using both a manual approach and the BIBOT software (2) published in English between 1.1.1975 and 31.12.2018. Within all extracted disease activity scores, we selected those with cut off values in four classes (remission, low, moderate and high disease activity). We used a linear interpolation to map all these disease activity scores to our new score, the AS-135, and developed a smart-phone application to perform the conversion automatically.

Results: 1068 articles were analyzed by BIBOT, 86 were excluded on the basis of the language used for their writing and 11 were excluded on the basis of their publication date. 599 were selected based on their titles, abstracts and keywords. 108 activity criteria from various fields (rheumatology, dermatology, gastroenterology, psychiatry, neurology and pneumology) were identified, but it is in rheumatology that we find separation into four classes. 10 scores met our

inclusion criteria and were implemented in the Android app. These are: DAS28 (ESR), DAS28 (CRP), SDAI, ASDAS (ESR), ASDAS (CRP), ESSDAI, SLEDAI-2K, DAPSA, PMR-AS (ESR) and PMR-AS (CRP). We built the AS135 score modification for each selected score using a linear interpolation of the existing criteria. It was defined on the interval $[0,10]$ and values 1,3 and 5 were used as thresholds. These arbitrary thresholds are then associated with the thresholds of the existing criteria and an interpolation can be calculated, allowing the conversion of the existing criteria into AS135 criterion. We have finally created a mobile application that allows each user to obtain both the original value of the activity criterion.

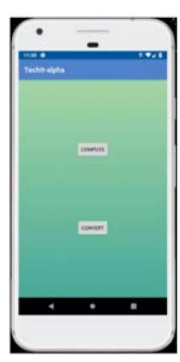

a)

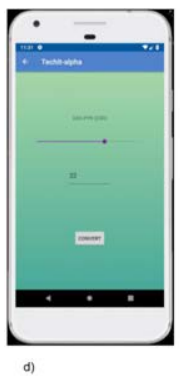

Conclusion: We have created a mobile application that allows any user to obtain in a simple way the level of disease activity, whatever the criterion used to describe it, since the application returns, in addition to the value of the activity criterion calculated from data returned by the physician, the transformation of this value into AS135 criterion and its interpretation in terms of level of activity of the pathology. The application is now available for Android devices and we plan to start developing a version for iOS devices.

\section{References:}

[1] Saraux L, Devauchelle-Pensec V, Saraux A. Plea for standardization of disease activity scores. Rheumatol Oxf Engl. 2019 Aug 1;58(8):1500-1

[2] Orgeolet L, Foulquier N, Misery L, Redou P, Pers J-O, Devauchelle-Pensec $\mathrm{V}$, et al. Can artificial intelligence replace manual search for systematic literature? Review on cutaneous manifestations in primary Sjögren's syndrome. Rheumatol Oxf Engl. 2019 Aug 31;

Disclosure of Interests: None declared

DOI: 10.1136/annrheumdis-2020-eular.1851

\section{THU0618-HPR PSYCHOSOCIAL CHANGES IN RHEUMATIC DISEASE: A NURSING LED CROSS-SECTIONAL STUDY}

R. Spagnuolo ${ }^{1}$, R. D. Grembiale ${ }^{2}$, F. S. laquinta ${ }^{2}$, V. Funari ${ }^{2}$, R. Pagnotta ${ }^{1}$, S. Naty ${ }^{2}$, P. Doldo ${ }^{1}{ }^{1}$ Magna Graecia University, School of Nursing, Catanzaro, Italy; ${ }^{2}$ Magna Graecia University, Rheumatology Research Unit, Catanzaro, Italy

Background: Nursing management in Rheumatic Diseases (RD) is focused on global patient care. Starting from basic knowledge of diagnostic and therapeutic management, nurses can assess the impact of RD on patients' quality of life not only at the physical level, but also at the psychological, social, and emotional levels.

Objectives: To evaluate psycosocial changes in RD patients through nursing-led Patient-Reported Outcomes

Methods: We performed a cross-sectional study of $100 \mathrm{RD}$ patients compared with 100 healthy volunteers matched for age, sex and BMI. Specialist nurses invited patients and volunteers to complete questionnaires on quality of life through seven domains (anxiety, depression, fatigue, sleep disturbance, pain interference, physical functions and satisfaction with participation in socia 